Article

\title{
Beneficial Effects of Melatonin in the Ovarian Transport Medium on In Vitro Embryo Production of Iberian Red Deer (Cervus elaphus hispanicus)
}

\author{
Irene Sánchez-Ajofrín ${ }^{1}{ }^{1}$, María Iniesta-Cuerda ${ }^{1}\left(\mathbb{D}\right.$, Patricia Peris-Frau ${ }^{1}(\mathbb{D}$, \\ Alicia Martín-Maestro ${ }^{1}$, Daniela-Alejandra Medina-Chávez ${ }^{1}{ }^{\circledR}$, Carolina Maside ${ }^{1}$, \\ María Rocío Fernández-Santos ${ }^{1}$, José Antonio Ortiz ${ }^{2}$, Vidal Montoro ${ }^{1}$, José Julián Garde ${ }^{1}$ (D) \\ and Ana Josefa Soler $1, *$ (D) \\ 1 SaBio IREC (CSIC-UCLM-JCCM), ETSIAM, Campus Universitario s/n, 02071 Albacete, Spain; \\ irene.sanchez.sa@gmail.com (I.S.-A.); Maria.IniestaCuerda@uclm.es (M.I.-C.); Patricia.Peris@uclm.es (P.P.-F.); \\ Alicia.MartinMaestro@uclm.es (A.M.-M.); Daniela.Medina@uclm.es (D.-A.M.-C.); \\ Carolina.Maside@uclm.es (C.M.); mrocio.fernandez@uclm.es (M.R.F.-S.); Vidal.montoro@uclm.es (V.M.); \\ Julian.garde@uclm.es (J.J.G.) \\ 2 Medianilla S.L. Finca Las Lomas, Vejer de la Frontera, 11179 Las Lomas, Cádiz, Spain; jaortiz@gruponetco.com \\ * Correspondence: anajosefa.soler@uclm.es
}

Received: 21 March 2020; Accepted: 24 April 2020; Published: 27 April 2020

check for updates

Simple Summary: The development of in vitro embryo production (IVP) in wild species, such as Iberian red deer, can become a daunting challenge since prolonged ovary transport times to the laboratory are often unavoidable. This may have detrimental effects on the quality and developmental capacity of oocytes. We evaluated the effect of supplementing the ovary transport medium with the antioxidant melatonin and observed an increased level of oocyte intracellular reduced glutathione content. Moreover, melatonin enhanced cleavage and blastocyst rates and had a positive effect on embryo quality in terms of the expression of essential embryo development-related genes. In conclusion, the addition of melatonin to the ovary storage medium could mitigate the negative impacts that long transport times may have on oocyte developmental competence and quality of the resulting blastocysts in Iberian red deer.

\begin{abstract}
A major limiting factor for the development of in vitro embryo production (IVP) in wild species, such as Iberian red deer, compared to livestock animals is the poor availability and limited access to biological material. Thus, the use of post-mortem ovaries from slaughtered animals represent a source of oocytes for the large scale production of embryos needed for research and to improve the efficiency of IVP. However, these oocytes are not as developmentally competent as their in vivo counterparts. Moreover, oocytes are usually obtained from ovaries that have been transported for long distances, which may also affect their quality. In order to overcome the issues associated with prolonged storage times of post-mortem material, in this study we examined the effect of melatonin supplementation to the ovary transport medium on oocyte quality, embryo yield, and blastocyst quality in Iberian red deer. When necessary, sheep was used as an experimental model due to the large number of samples required for analysis of oocyte quality parameters. Oocytes were in vitro matured and assessed for early apoptosis; DNA fragmentation; reactive oxygen species (ROS); reduced glutathione (GSH) content, mitochondrial membrane potential, and distribution; and relative abundance of mRNA transcript levels. After in vitro fertilization, embryo rates and blastocyst quality were also investigated. The results revealed that melatonin treatment significantly increased intracellular level of GSH in sheep oocytes. Moreover, the percentage of cleavage and blastocyst yield in red deer was greater compared to the Control group and there was lower abundance of oxidative stress- and apoptosis-related SHC1, TP53, and AKR1B1 mRNA transcripts in blastocysts for the Melatonin group. In conclusion, the supplementation of melatonin to the ovary storage medium
\end{abstract}


had a positive effect on the developmental competence and quality of resulting blastocysts in Iberian red deer.

Keywords: melatonin; deer; sheep; ovary storage; transport; oocyte; embryo

\section{Introduction}

The Iberian red deer (Cervus elaphus hispanicus) is a wild subspecies of red deer that only inhabits the Iberian Peninsula. Its genetic value is well-known worldwide and the production of this subspecies is related to the hunting industry for commercial purposes. The use of assisted reproduction technologies, like in vitro embryo production (IVP), in red deer had been previously acknowledged $[1,2]$ and may play an important role for the purpose of improving individuals for trophy hunting and ensuring genetic advancement and avoidance of inbreeding depression as a result of the genetic isolation of wild populations within fenced game estates [2,3]. Additionally, though Iberian red deer is not endangered, its conservation is highly recommended [4].

Unfortunately, the process of developing IVP protocols and improving its efficiency in wild species is a daunting challenge due to biological and technical aspects; it requires large numbers of experimental samples and there is often limited access to the animals of study $[5,6]$. In that scenario, the use of ovaries of slaughtered animals can be a source of oocytes for the large scale production of embryos through IVP procedures [7]. However, compared to in vivo counterparts, the harvesting of follicular oocytes from dead animals is known to produce less developmentally competent oocytes [8]. In the case of Iberian red deer it is possible to obtain ovaries from animals slaughtered in abattoirs or slaughterhouse-like designated facilities. However, these places are usually far from laboratories. Although in vitro embryos have been successfully produced in this deer subspecies from dead animals [2], blastocyst rates remain low compared to other small ruminants like sheep [9].

After slaughter, the lack of irrigation places the ovaries under ischemic conditions, reducing oxygen and energy supplies [10]. In this situation, the production of reactive oxygen species (ROS) may be increased within the follicle [11], overwhelming the endogenous antioxidant systems, thus leading to oxidative stress and oocyte damage [12,13]. To reduce the harmful effects of ROS in the oocyte, several antioxidants have been used during in vitro maturation (IVM) [14], though their supplementation may be more favorable at an earlier stage. Interestingly, Zhau and Zou [15] showed that a rapid increase in the levels of circulating ROS can occur three minutes after the onset of ischemia in rat cardiac tissue. Moreover, of all adult organs in mammals, female reproductive tissues have some of the greatest rates of blood flow per unit of tissue and also exhibit a high metabolic rate [16]. Therefore, in ischemic reproductive organs, the increase of oxygen free radicals might take place as quickly as in other metabolically "expensive" tissues and organs such as heart, kidneys, and brain [17]. Hence, it is very likely that the addition of antioxidants to the ovary storage medium has a crucial role in germ cell protection, especially when long ovary transport times cannot be avoided.

Antioxidants are helpful for minimizing oxidative stress induced by excessive ROS production by clearing free radicals and lowering ROS levels [18]. Accordingly, melatonin (N-Acetyl-5-Methoxy Tryptamine) is a powerful direct scavenger of free radicals with antioxidant and antiapoptotic properties [19]. The ability of melatonin to protect against oxidative stress has been extensively studied during IVM and in vitro culture (IVC), and has demonstrated a positive effect in different species such as cattle [20,21], sheep [22], mouse [23], pig [24-27], and rabbit [28]. These beneficial effects have been attributed to its ability to decrease the expression of proapoptotic genes, increase that of antiapoptotic genes, and neutralize ROS [29]. However, there is limited information about the effect of melatonin during long ovary transports. In this respect, Goodarzi et al. [30] showed good results of this antioxidant in terms of oocyte developmental competence and blastocyst quality in sheep. This study also revealed that the storage of ovaries at $20^{\circ} \mathrm{C}$ compared to $4{ }^{\circ} \mathrm{C}$ adversely affected the 
ability of oocytes to develop to the blastocyst stage. It is known that temperature, medium composition, and storage time are determinant factors in organ preservation [11,31]. This has been shown in several studies where ovary transport conditions influenced IVP success rates in different species [10,32-35]. Although the effect of temperature during shipment of ovaries has been examined in Iberian red deer [2], to the best of our knowledge, there are no reports regarding the impact of an antioxidant in the ovary preservation medium in this species.

For the purpose of improving the current poor in vitro fertilization (IVF) outcomes in Iberian red deer, the goal of this study was to evaluate the effects of supplementing the ovary transport medium with melatonin on oocyte quality, embryo production, and blastocyst quality. Due to the low availability of Iberian red deer samples and the great number of oocytes required for analysis of oocyte quality, parameters such as ROS and glutathione (GSH) content; early apoptosis; DNA fragmentation; and mitochondrial membrane potential and distribution were evaluated in sheep since it is a valuable research model [30].

\section{Materials and Methods}

Except where otherwise stated, all chemicals and media were acquired from Merck Life Sciences (Madrid, Spain).

\subsection{Recovery of Oocytes and In Vitro Maturation}

Ovaries were collected from animals slaughtered in slaughterhouse. Handling of those animals followed the Spanish Policy for the care of animals, their exploitation, transport, experimentation, and slaughter (Law 32/2007).

Ovaries of adult sheep and Iberian red deer were collected post-mortem from a local abattoir and a slaughterhouse-like designated facility, respectively, during spring season. These were transported to the laboratory at $30{ }^{\circ} \mathrm{C}$ and randomly divided between the two treatment conditions: $8.9 \mathrm{~g} / \mathrm{L}$ physiological saline and $0.1 \mathrm{~g} / \mathrm{L}$ penicillin (Control) or $8.9 \mathrm{~g} / \mathrm{L}$ physiological saline, $0.1 \mathrm{~g} / \mathrm{L}$ penicillin, and $10^{-3} \mathrm{M}$ melatonin (Melatonin). The stored ovaries from deer and sheep were processed between $7 \mathrm{~h}$ and $11 \mathrm{~h}$ after slaughter of the animal. To obtain the cumulus-oocyte complexes (COCs), ovaries were sliced with a scalpel in TCM199 medium supplemented with HEPES $(2.38 \mathrm{mg} / \mathrm{mL})$, heparin $(2 \mu \mathrm{L} / \mathrm{mL})$, and gentamycin $(4 \mu \mathrm{L} / \mathrm{mL})$. The COCs (sheep $=1227$ and deer $=445$ ) were then washed in TCM199 and $4 \mu \mathrm{L} / \mathrm{mL}$ gentamycin, and those encircled by at least three layers of compact cumulus cells and a homogeneous ooplasm were selected and added to four-well dishes containing $500 \mu \mathrm{L}$ of IVM medium/TCM199 supplemented with $4 \mu \mathrm{L} / \mathrm{mL}$ of gentamycin, $100 \mu \mathrm{M}$ of cysteamine, $10 \mathrm{mg} / \mathrm{mL} \mathrm{of} \mathrm{FSH,}$ $10 \mathrm{mg} / \mathrm{mL}$ of LH, and 10\% fetal calf serum (FCS) [2] under mineral oil (Nidacon, Gothenburg, Sweden). Oocytes were cultured for approximately $22 \mathrm{~h}$ at $38.5{ }^{\circ} \mathrm{C}$ in a humidified atmosphere with $5 \% \mathrm{CO}_{2}$ in air. After maturation, 133 oocytes in sheep and 76 in deer were collected and mechanically denuded of cumulus cells, snap-frozen in liquid nitrogen, and stored at $-80{ }^{\circ} \mathrm{C}$ until mRNA extraction and reverse transcription.

\subsection{Collection of Follicular Fluid and Melatonin ELISA Assay}

Follicular fluid from Control and Melatonin sheep ovaries was collected in a sterile Eppendorf ${ }^{\circledR}$ $1.5 \mathrm{~mL}$ tube. Follicular fluid was subjected to $15 \mathrm{~min}$ of centrifugation at a speed of $3300 \mathrm{rpm}$ at $4{ }^{\circ} \mathrm{C}$. Afterward, supernatant was centrifuged again in the same conditions. The concentrations of melatonin in the follicular fluid were determined by Melatonin saliva ELISA kits (Tecan-IBL International, Hamburg, Germany). All ELISA experiments were run in compliance with the manufacturer's protocol. Melatonin levels were determined as average levels.

\subsection{In Vitro Fertilization}

Sheep and red deer matured COCs were washed and the cumulus cells were partially removed from the oocytes by gentle pipetting. Sperm samples were supplied by the Germplasm Bank of 
Universidad de Castilla-La Mancha (UCLM). The Germplasm Bank of UCLM is officially authorized for storing semen (ES07RS02OC) following the RD 841/2011. Frozen straws from two rams and three deer were thawed and spermatozoa were centrifuged over a Percoll ${ }^{\circledR}$ gradient $(45 \% / 90 \%)$. Selected spermatozoa were capacitated for $15 \mathrm{~min}$ at $38.5^{\circ} \mathrm{C}$ and $5 \% \mathrm{CO}_{2}$ in $450 \mu \mathrm{L}$ of in vitro fertilization (IVF) medium: synthetic oviductal fluid (SOF), as established by Takahashi and First [36], supplemented with $10 \%$ estrous sheep serum (ESS) in sheep, and $450 \mu \mathrm{L}$ of a modified SOF $\left(5 \mathrm{mM} \mathrm{CaCl} 2 \cdot 2 \mathrm{H}_{2} \mathrm{O}\right)$ supplemented with $20 \%$ ESS in deer, as previously described by Sánchez-Ajofrín et al. [9]. Spermatozoa and oocytes were co-incubated under mineral oil (Nidacon, Gothenburg, Sweden) at $38.5{ }^{\circ} \mathrm{C}$ in $5 \%$ $\mathrm{CO}_{2}, 5 \% \mathrm{O}_{2}$, and $90 \% \mathrm{~N}_{2}$ air with high humidity. A final sperm concentration of $10^{6}$ spermatozoa $/ \mathrm{mL}$ was used for insemination, and groups of approximately 40 oocytes were placed in each well.

\subsection{In Vitro Embryo Culture}

At approximately $18 \mathrm{~h}$ after IVF, presumptive zygotes were washed four times and transferred to four-well plates containing $25 \mu \mathrm{L}$ droplets of IVC medium: SOF supplemented with $3 \mathrm{mg} / \mathrm{mL}$ of bovine serum albumin (BSA) under $750 \mu \mathrm{L}$ of mineral oil (Nidacon, Gothenburg, Sweden). Embryos were incubated at $38.5^{\circ} \mathrm{C}$ in $5 \% \mathrm{CO}_{2}, 5 \% \mathrm{O}_{2}$, and $90 \% \mathrm{~N}_{2}$ air with high humidity for 8 days post-insemination (dpi). Cleavage rate was evaluated at $48 \mathrm{~h}$ post-insemination (hpi), and blastocyst rate was recorded on 6, 7, and 8 dpi. All expanded blastocysts were washed three times in PBS supplemented with $0.1 \% w / v$ PVA (PBS-PVA) and either snap-frozen and stored at $-80{ }^{\circ} \mathrm{C}$ until mRNA analysis or fixed in a $100 \mu \mathrm{L}$ drop of glutaraldehyde solution ( $4 \% w / v$ in PBS, $\mathrm{pH} 7.4)$ at room temperature for cell-number evaluation.

\subsection{Determination of Early Apoptosis}

The detection of early apoptosis in sheep oocytes was performed with the Annexin V, FITC conjugate kit (Invitrogen, Barcelona, Spain) following the manufacturer's instructions with slight modifications. Briefly, 100 in vitro-matured sheep oocytes were mechanically denuded and placed in $100 \mu \mathrm{L}$ Annexin V binding buffer droplets containing $5 \mu \mathrm{L}$ of Annexin V/FITC and $1 \mu \mathrm{L}$ of propidium iodide (PI; $100 \mu \mathrm{g} / \mathrm{mL}$ ) and incubated at $37^{\circ} \mathrm{C}$ in the dark for $15 \mathrm{~min}$. Oocytes were counterstained with PI, a membrane impermeable stain, to distinguish between live cells and dead cells. After incubation, oocytes were washed thrice in PBS-PVA, mounted on slides and observed by fluorescence microscopy (Eclipse 80i, Nikon Instruments Europe, Amsterdam, Netherlands). Oocytes were classified into three groups: (1) viable oocytes, negative for Annexin V and PI signal (Figure 1A); (2) early apoptotic oocytes, positive for Annexin $\mathrm{V}$ green staining of the ooplasmic membrane and PI negative (Figure 1B); and (3) non-viable oocytes, with Annexin V and PI positive signals (Figure 1C) or negative for Annexin $\mathrm{V}$ and positive for PI signal (Figure 1D).
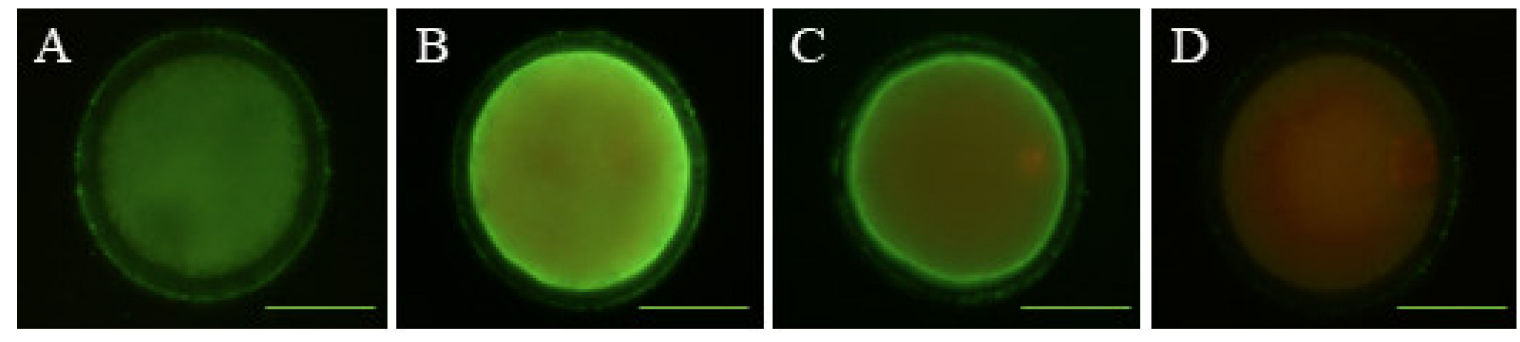

Figure 1. Representative images of early apoptosis detection in sheep oocytes. Oocytes were stained by Annexin V and PI. (A) Viable oocytes; (B) early apoptotic oocytes; (C,D) non-viable oocytes. Scale bar $=52 \mu \mathrm{M}$.

\subsection{Detection of DNA Fragmentation}

Denuded in vitro-matured sheep oocytes ( $n=93$ ) were fixed in $0.5 \% v / v$ glutaraldehyde for $20 \mathrm{~min}$ at room temperature and stored in PBS-PVA at $4{ }^{\circ} \mathrm{C}$ before TUNEL assay (Tdt-mediated dUTP nick-end 
labelling). Fixed samples were permeabilized in 0.5\% Triton X-100 in PBS for $1 \mathrm{~h}$ at room temperature. Next, positive control samples were incubated with DNAse $(0.2 \mathrm{U} / \mu \mathrm{L})$ at $37^{\circ} \mathrm{C}$ in the dark for $1 \mathrm{~h}$. Immediately after, the In Situ Cell Death Detection Kit, fluorescein (Merck Life Sciences, Madrid, Spain) was used for TUNEL staining according to the manufacturer's instructions. Samples were placed in $30 \mu \mathrm{L}$ droplets of TUNEL reagent containing fluorescein isothiocyanate conjugated dUTP and the enzyme terminal deoxynucleotidyl transferase (TdT) and then incubated in the dark for $1 \mathrm{~h}$ at $37^{\circ} \mathrm{C}$. The negative control was incubated in the absence of TdT. Afterward, matured oocytes were washed three times in PBS-PVA and transferred onto slides in a drop of SlowFade ${ }^{\mathrm{TM}}$ Gold Antifade Mountant with $6.25 \mu \mathrm{g} / \mathrm{mL}$ PI and $1 \mu \mathrm{g} / \mathrm{mL}$ Hoechst 3342 fluorescent dye, respectively. Samples were evaluated using a fluorescence microscope (Nikon Eclipse 80i). Stages of apoptosis were classified as TUNEL-positive (Figure 2A) and TUNEL-negative (Figure 2B) according to fragmented cell nuclei.
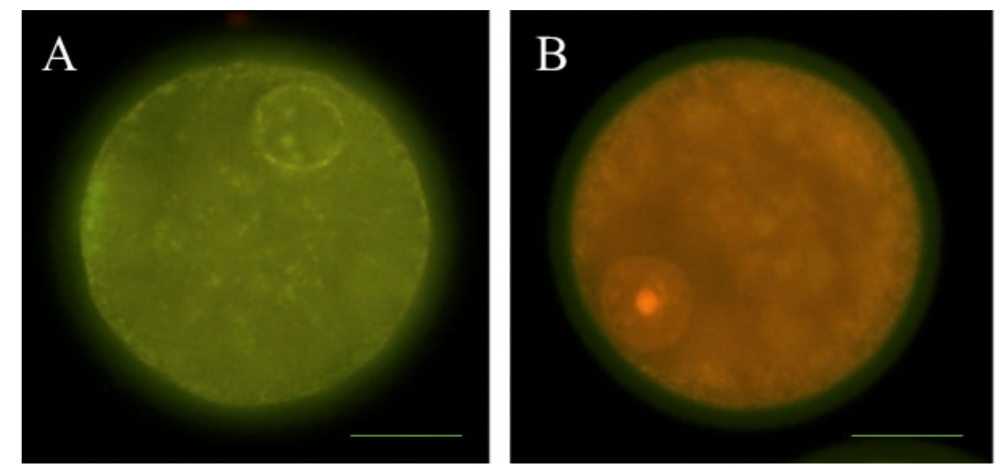

Figure 2. Representative images of DNA fragmentation by TUNEL assay in sheep oocytes at the germinal vesicle (GV) stage. (A) TUNEL-positive oocyte; (B) TUNEL-negative oocyte. Scale bar $=38 \mu \mathrm{M}$.

\subsection{Determination of Intracellular ROS and GSH Levels}

To detect intracellular ROS and GSH levels, a total of 133 denuded in vitro-matured sheep oocytes were incubated with $10 \mu \mathrm{M}$ of $2^{\prime}, 7^{\prime}$-dichlorodihydrofluorescein diacetate $\left(\mathrm{CM}-\mathrm{H}_{2} \mathrm{DCFDA}\right.$; Invitrogen, Barcelona, Spain) and 50 of $\mu \mathrm{M}$ CellTracker ${ }^{\mathrm{TM}}$ Blue $\mathrm{CMF}_{2} \mathrm{HC}$ dye (Thermo Fisher Scientific, Barcelona, Spain), respectively, for $30 \mathrm{~min}$ at $37^{\circ} \mathrm{C}$ in the dark. After incubation, oocytes were washed thrice with PBS-PVA and placed on glass slides under cover slips. The images were observed with a fluorescence microscope (Eclipse 80i, Nikon Instruments Europe, Amsterdam, Netherlands) and the fluorescence intensity was analyzed by ImageJ 1.45 s software (National Institutes of Health, Bethesda, Rockville, MD, USA). Oocytes were classified as having a high (Figure 3A) or low (Figure 3B) ROS intensity and high (Figure 3C) or low (Figure 3D) GSH intensity.
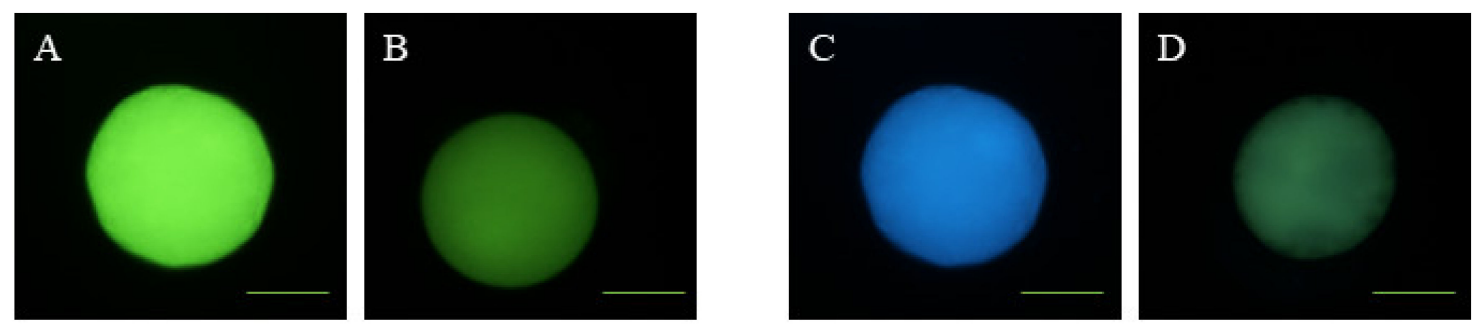

Figure 3. Representative images of reactive oxygen species (ROS) and glutathione (GSH) levels in sheep oocytes. (A) High ROS intensity; (B) low ROS intensity; (C) high GSH intensity; (D) low GSH intensity. Scale bar $=51 \mu \mathrm{M}$.

\subsection{Mitochondrial Membrane Potential Analysis}

To monitor mitochondrial membrane potential changes, 96 denuded in vitro-matured sheep oocytes were incubated with $2 \mu \mathrm{M}$ JC-1 dye (5,5',6,6'-tetrachloro-1,1',3,3'-tetraethylbenzimidazolyl-carbocyanine 
iodide (Thermo Fisher Scientific, Barcelona, Spain). All oocytes were stained at $37^{\circ} \mathrm{C}$ for $30 \mathrm{~min}$. This reagent is a cell permeant dye that exhibits two emission peaks of green fluorescence and red fluorescence to indicate J-monomers (low mitochondrial membrane polarization) and J-aggregates (high mitochondrial membrane polarization). Relative mitochondrial membrane potential was calculated using ImageJ 1.45 s software as the ratio of red fluorescence (activated mitochondria/J-aggregates; Figure 4A) to green fluorescence (less-activated mitochondria/J-monomers: Figure 4B).
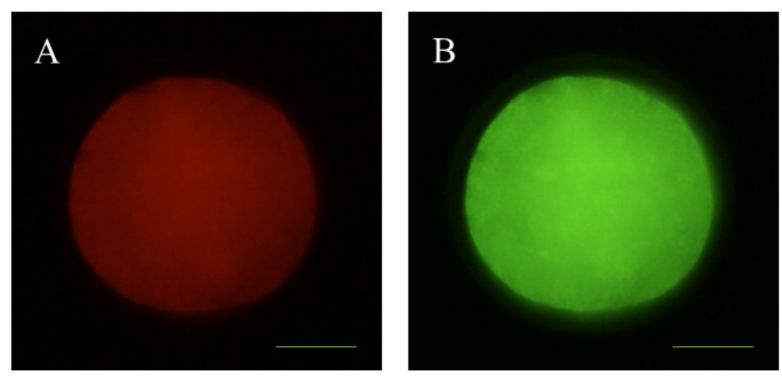

Figure 4. Representative images of JC-1 stained mitochondria in sheep oocytes. (A) Mitochondria with high membrane potential (red fluorescence); (B) mitochondria with low membrane potential (green fluorescence). Scale bar $=21 \mu \mathrm{M}$.

\subsection{Examination of Mitochondrial Distribution}

The mitochondrial distribution pattern was examined by MitoTracker ${ }^{\circledR}$ Red CMXRos (Thermo Fisher Scientific, Barcelona, Spain). A total of 100 denuded in vitro-matured sheep oocytes were incubated for $20 \mathrm{~min}$ at $37^{\circ} \mathrm{C}$ in $100 \mathrm{nM}$ dye. The labeled oocytes were washed twice for $5 \mathrm{~min}$, placed on glass slides, and examined by fluorescence microscopy (Eclipse 80i, Nikon Instruments Europe, Amsterdam, Netherlands). Mitochondrial distribution was categorized into two categories according to cytoplasm oocyte distribution: homogeneous (normal) distribution (Figure 5A) and abnormal distribution (Figure 5B).
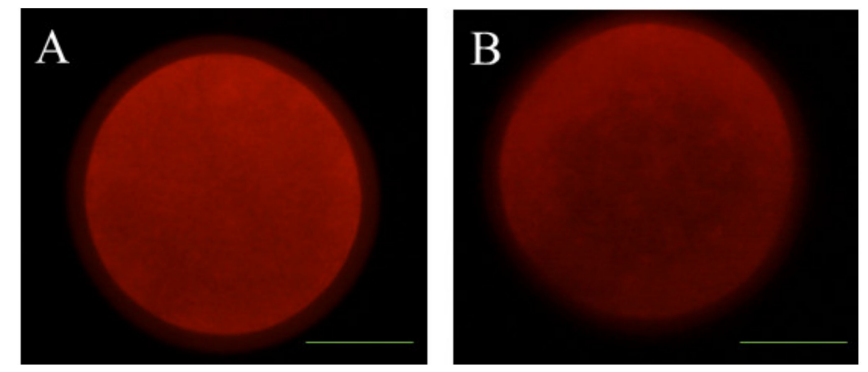

Figure 5. Representative images of mitochondrial distribution of sheep oocytes. (A) Red mitochondria normally distributed (homogeneous distribution; Figure 5A); (B) red mitochondria abnormally distributed (Figure 5B). Scale bar $=24 \mu \mathrm{M}$.

\subsection{In Vitro Maturation Assessment}

A total of 182 denuded sheep oocytes were fixed in $0.5 \%$ glutaraldehyde $(v / v)$ for 20 min at room temperature. Subsequently, oocytes were incubated in one drop of SlowFade ${ }^{\mathrm{TM}}$ Gold Antifade Mountant containing $1 \mu \mathrm{g} / \mathrm{mL}$ Hoechst 33342 in PBS-PVA for $10 \mathrm{~min}$. Fixation and Hoechst 33342 staining procedures were performed at room temperature. After every staining or fixing procedure, oocytes were washed three times in PBS-PVA and mounted on slides sealed under coverslips with vaseline. After $20 \mathrm{~min}$, nuclear configurations were assessed using an epifluorescent microscope (Eclipse 80i, Nikon Instruments Europe, Amsterdam, Netherlands). Chromatin configurations were classified as follows: immature or germinal vesicle $(\mathrm{GV})$, when the vesicle was clearly visible; resumption of meiosis or germinal vesicle break down (GVBD), when the chromatin was dispersed and initiating 
condensation; metaphase I (MI), when chromosomes became arranged on the metaphase plate and were attached to the meiotic spindle; and mature or metaphase II (MII), when chromosomes were in the second metaphase plate and the first polar body was extruded.

\subsection{Transcript Quantification by $q P C R$}

A total of 133 oocytes and 71 blastocysts in sheep and 76 oocytes and 28 blastocysts in red deer were processed for RNA extraction and cDNA synthesis and were submitted to qPCR as previously described [9]. Poly(A) RNA was extracted from pools of 10-14 expanded sheep blastocysts and approximately five expanded red deer blastocysts per experimental group (three replicates) using magnetic beads (Dynabeads ${ }^{\circledR}$ mRNA DIRECT ${ }^{\mathrm{TM}}$ Micro Kit; Invitrogen ${ }^{\mathrm{TM}}$, Carlsbad, California, USA) according to the manufacturer's guidelines slightly modified by Bermejo-Álvarez et al. [37]. Briefly, each pool of oocytes and blastocysts was resuspended in $50 \mu \mathrm{L}$ of lysis/binding buffer for $5 \mathrm{~min}$ at room temperature. The resulting lysate was then hybridized with $10 \mu \mathrm{L}$ of prewashed oligo (dT)25 beads. After $5 \mathrm{~min}$ of incubation, samples were put into a magnet to remove the lysis buffer while retaining the poly(A) RNA attached to the beads. After hybridization, samples were washed twice in $50 \mu \mathrm{L}$ of wash buffer A and twice in wash buffer B. Next, the mRNA samples were eluted from the beads with $28 \mu \mathrm{L}$ of elution buffer (Tris- $\mathrm{HCl}$ ). Following this, reverse transcription (RT) was performed using the iScript ${ }^{\mathrm{TM}} \mathrm{CDNA}$ Synthesis Kit (Bio-Rad, Madrid, Spain) in a total volume of $40 \mu \mathrm{L}$. In the first step, samples were heated to $70^{\circ} \mathrm{C}$ for $5 \mathrm{~min}$ to denature the secondary RNA structure. First-strand cDNA was generated from the total amount of RNA by adding $4 \mu \mathrm{L}$ of iScript Reaction Mix $(5 x), 1 \mu \mathrm{L}$ of iScript Reverse Transcriptase, and $7 \mu \mathrm{L}$ of nuclease-free water. The RT reaction was performed at the following conditions: $10 \mathrm{~min}$ at $25^{\circ} \mathrm{C}$, followed by $30 \mathrm{~min}$ at $42{ }^{\circ} \mathrm{C}$ and $5 \mathrm{~min}$ at $85{ }^{\circ} \mathrm{C}$.

After RT, the relative abundance of mRNA transcripts was determined by quantitative real-time PCR (qPCR) using a LightCycler 480 II System (Roche Diagnostics, Barcelona, Spain). The qPCR samples consisted of $10 \mu \mathrm{L}$ of PowerUp ${ }^{\mathrm{TMSYBR}}{ }^{\circledR}$ Green Master Mix (Thermo Fisher Scientific, Barcelona, Spain), $200 \mathrm{nM}$ each of forward and reverse primers, and $2 \mu \mathrm{L}$ of cDNA template. Final volume of $20 \mu \mathrm{L}$ was reached by adding nuclease-free water. The PCR amplification was carried out in the following cycling conditions: $50{ }^{\circ} \mathrm{C}$ for $2 \mathrm{~min}$ for UDG activation, $95^{\circ} \mathrm{C}$ for $2 \mathrm{~min}$, and then 40 cycles of $95{ }^{\circ} \mathrm{C}$ for $15 \mathrm{~s}$ and $60^{\circ} \mathrm{C}$ for $1 \mathrm{~min}$. Finally, a melting curve was produced to confirm the presence of a single gene by heating the samples to $95{ }^{\circ} \mathrm{C}$ for $5 \mathrm{~s}$ in a ramp rate of $4.4{ }^{\circ} \mathrm{C} / \mathrm{s}$, followed by $65{ }^{\circ} \mathrm{C}$ for 1 min with a heating rate of $2.2^{\circ} \mathrm{C} / \mathrm{s}$, and continuous fluorescence measurement. Two technical replicates per biological replicate and individual gene were evaluated and reactions without any cDNA template ( $2 \mu \mathrm{L}$ nuclease-free water) were used as the negative control.

Sixteen separate genes, aldo-keto reductase family 1, member B1 (AKR1B1); BCL2-associated X protein $(B A X)$; BCL2 apoptosis regulator (BCL2); bone morphogenetic protein 15 (BMP15); gap junction protein alpha 1 (GJA1); glutathione peroxidase 1 (GPX1); growth differentiation factor 9 (GDF9); fibroblast growth factor 8 (FGF8); growth factor 16 (FGF16); insulin-like growth factor 2 receptor (IGF2R); integral membrane protein 2B (ITM2B); nuclear respiratory factor 1 (NRF1); DNA polymerase gamma 2, accessory subunit (POLG2); SHC adaptor protein (SHC1); superoxide dismutase (SOD2); and tumor protein p53 (TP53), plus an endogenous reference gene (H2A histone family, member Z; H2AFZ), were amplified (see Table 1 for all primer information). The comparative cycle threshold (Ct) method [38] was used to calculate the relative transcript abundances with the average of two replicates, and quantification was normalized against that of the endogenous control (H2AFZ). Fold changes in the relative abundance of mRNA transcripts were determined for target genes assuming an amplification efficiency of $100 \%$ and were calculated using the $2^{-\Delta \Delta C T}$ method [39]. 
Table 1. Details of primers used in this study for qPCR.

\begin{tabular}{|c|c|c|c|c|}
\hline Gene & Gene Function & Primer Sequence $\left(5^{\prime}-3^{\prime}\right)$ & Product Size (bp) & Accession No. \\
\hline$H 2 A F Z$ & Reference gene & $\begin{array}{c}\text { F-ATTGCTGGTGGTGGTGTCAT } \\
\text { R-ACTGGAATCACCAACACTGGA }\end{array}$ & 147 & NM_001009270.1 \\
\hline SOD2 & \multirow[b]{2}{*}{ Oxidative stress } & $\begin{array}{l}\text { F-GCTTACAGATTGCTGCTTGT } \\
\text { R-AAGGTAATAAGCATGCTCCC }\end{array}$ & 101 & NM_201527.2 \\
\hline GPX1 & & $\begin{array}{c}\text { F-GCAACCAGTTTGGGCATCA } \\
\text { R-CTCGCACTTTTCGAAGAGCATA }\end{array}$ & 116 & NM_174076.3 \\
\hline SHC1 & \multirow{5}{*}{ Apoptosis } & $\begin{array}{l}\text { F-GTGAGGTCTGGGCAGAAGC } \\
\text { R-GGTTCGGACAAAAGGATCACC }\end{array}$ & 335 & XM_024986737.1 \\
\hline TP53 & & $\begin{array}{l}\text { F-GACTCTCGTGGTAACCTGCT } \\
\text { R-AATTTTCTTCCTCAGTGCGGC }\end{array}$ & 91 & NM_001009403.1 \\
\hline $\operatorname{ITM} 2 B^{\mathrm{a}}$ & & $\begin{array}{l}\text { F-GTCCCAGAGTTTGCAGATAGTGA } \\
\text { R-GGAATCACATAGCACTTATCCAGGTT }\end{array}$ & 104 & NM_001035093.1 \\
\hline$B A X^{\mathrm{b}}$ & & $\begin{array}{l}\text { F-GTTGTCGCCCTTTTCTACTTTGC } \\
\text { R-CAGCCCATGATGGTCCTGATC }\end{array}$ & 89 & NM_173894.1 \\
\hline BCL2 & & $\begin{array}{l}\text { F-GGAGCTGGTGGTTGACTTTC } \\
\text { R-CTAGGTGGTCATTCAGGTAAG }\end{array}$ & 518 & NM_001077486.2 \\
\hline$N R F 1^{\mathrm{c}}$ & \multirow{2}{*}{ Transcription factor } & $\begin{array}{l}\text { F-CTGTCGCCCAAGTGAATTATTCG } \\
\text { R-TGTAACGTGGCCCAGTTTTGT }\end{array}$ & 67 & NM_001098002.2 \\
\hline POLG2 d & & $\begin{array}{l}\text { F-CTTCTGGGAAACTACGGGAGAAC } \\
\text { R-GTAGCCTCTTGTTTACCAGATCCA }\end{array}$ & 84 & NM_001075191.1 \\
\hline$A K R 1 B 1$ & Implantation & $\begin{array}{l}\text { F-CGTGATCCCCAAGTCAGTGA } \\
\text { R-AATCCCTGTGGGAGGCACA }\end{array}$ & 152 & NM_001012519.1 \\
\hline$I G F 2 R$ & Growth factor & $\begin{array}{l}\text { F-GCTGCGGTGTGCCAAGTGAAAAAG } \\
\text { R-AGCCCCTCTGCCGTTGTTACCT }\end{array}$ & 201 & NM_174352.2 \\
\hline GJA1 & GAP junctions & $\begin{array}{l}\text { F-TGCCTTTCGTTGTAACACTCA } \\
\text { R-AGAACACATGAGCCAGGTACA }\end{array}$ & 143 & NM_174068.2 \\
\hline$B M P 15^{\mathrm{e}}$ & \multirow{4}{*}{ Oocyte maturation } & $\begin{array}{l}\text { F-CTACGACTCCGCTTCGTGTGT } \\
\text { R-AGTGCCATGCCACCAGAAC }\end{array}$ & 69 & NM_001031752.1 \\
\hline$G D F 9^{\mathrm{f}}$ & & $\begin{array}{l}\text { F-GAAGTGGGACAACTGGATTGTG } \\
\text { R-CCCTGGGACAGTCCCCTTTA }\end{array}$ & 71 & NM_174681.2 \\
\hline FGF8 $\mathrm{g}$ & & $\begin{array}{l}\text { F-GGAGATCGTGCTGGAGAACAA } \\
\text { R-GCCATGTACCAGCCCTCGTA }\end{array}$ & 66 & NM_001206678.1 \\
\hline$F G F 16^{\mathrm{h}}$ & & $\begin{array}{l}\text { F-CGCTTCGGAATTCTGGAGTT } \\
\text { R-TCCACTCCCCGGATGCT }\end{array}$ & 62 & NM_001192777.1 \\
\hline
\end{tabular}

F, forward primer; R, reverse primer. ${ }^{\text {a-h }}$ From Ferreira et al. [40].

\subsection{Statistical Analysis}

Melatonin concentration in follicular fluid; oocyte early apoptosis; DNA fragmentation; ROS and GSH content; mitochondrial membrane potential and distribution; meiotic competence; embryo production; and total number of cells in blastocysts were analyzed by factorial ANOVA with the SPSS 24.0 software (IBM, Armonk, NY, USA), after confirming that data were distributed normally and variances were homogeneous. With this analysis, type of ovary storage medium (Melatonin and Control) and the replicate (for embryo production, five replicates; for evaluation of oocyte early apoptosis; DNA fragmentation; ROS and GSH content; mitochondrial membrane potential and distribution; meiotic competence; and total number of cells in blastocysts, three replicates) were considered fixed effects. Additionally, another factorial ANOVA was conducted to examine the relative abundances of mRNA transcripts, with type of ovary storage media and qPCR technical replicate (two replicates) as the fixed effects and the different target genes as the dependent variable. When a significant effect was observed, post hoc comparisons with Bonferroni correction were carried out. Results are presented as mean \pm S.E.M. 


\section{Results}

\subsection{Melatonin Addition to the Ovary Storage Medium Increases Melatonin Levels in Follicular Fluid}

As shown in Figure 6, melatonin concentration in follicular fluid was increased $(p<0.01)$ when comparing the Melatonin group to the Control group $(35.58 \pm 1.41 \mathrm{pg} / \mathrm{mL}$ and $18.11 \pm 1.41 \mathrm{pg} / \mathrm{mL}$, respectively).

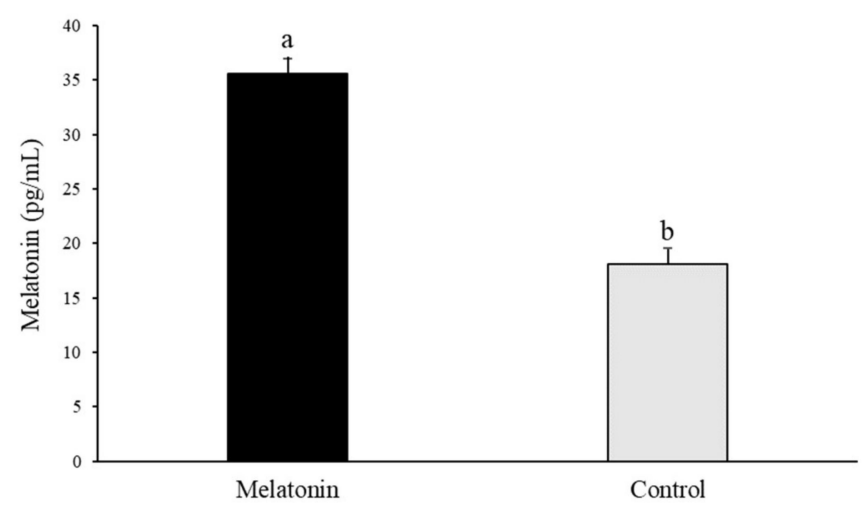

Figure 6. Melatonin concentrations (pg/mL) in samples of follicular fluid collected from sheep ovaries transported in saline solution (Control) and saline solution with $10^{-3} \mathrm{M}$ melatonin (Melatonin); Results are expressed as mean \pm SEM; ${ }^{a}, b$ Different letters indicate differences $(p \leq 0.05)$ among treatments.

\subsection{Effects of Melatonin on Oocyte Quality}

Early apoptosis and DNA fragmentation assessed by Annexin V and TUNEL staining, respectively, in the Melatonin and Control groups did not show differences ( $p>0.05$; Figure 7A).
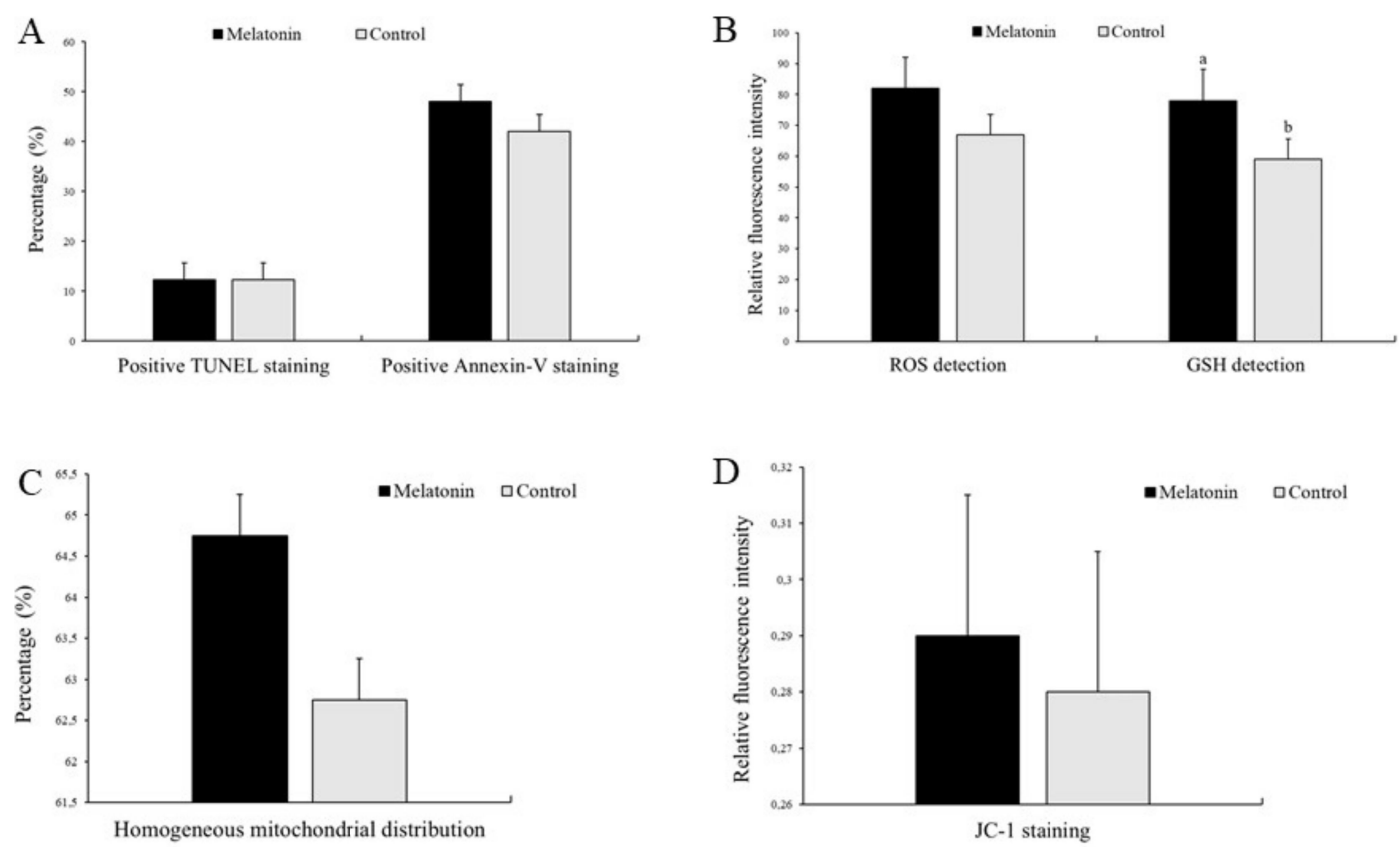

Figure 7. Effect of melatonin supplementation on sheep oocytes' (A) early apoptosis (positive Annexin V staining) and DNA fragmentation (positive TUNEL staining); (B) ROS and GSH levels; (C) homogeneous mitochondrial distribution; (D) mitochondrial membrane potential: red (high membrane potential)/green (low membrane potential) fluorescence ratio (JC-1 staining); Results are expressed as mean \pm SEM; ${ }^{a, b}$ Different letters indicate differences $(p \leq 0.05)$ among treatments. 
Impaired ROS and GSH balance is considered one of the main factors leading to oxidative stress. As shown in Figure 7B, Melatonin and Control-derived oocytes did not exhibit different $(p>0.05)$ levels of ROS. However, melatonin treatment increased $(p<0.05)$ intracellular GSH content as compared to Control (78.01 \pm 6.64 and $59.02 \pm 6.64$, respectively).

Since mitochondria contribute significantly to cellular processes of both ROS production and apoptosis, we examined mitochondrial distribution and membrane potential in oocytes after melatonin supplementation. As shown in Figure 7C, most of the Melatonin and Control-derived oocytes had a normal mitochondrial distribution, with no differences $(p>0.05)$ among groups. Furthermore, the ratio of red to green JC-1 fluorescence did not show differences $(p>0.05)$ between Melatonin and Control oocytes (Figure 7D).

We also measured the mRNA transcript relative abundance pattern of genes of interest in red deer oocytes. As shown in Figure 8, there were no differences $(p>0.05)$ between treatments in terms of relative mRNA transcript levels. In addition, relative abundance of mRNA transcripts was also analyzed in sheep oocytes, as a complementary assay to deer results, and showed that melatonin supplementation increased the relative abundance of ITM2B mRNA transcript compared to Control $(p<0.05$; Figure S1).

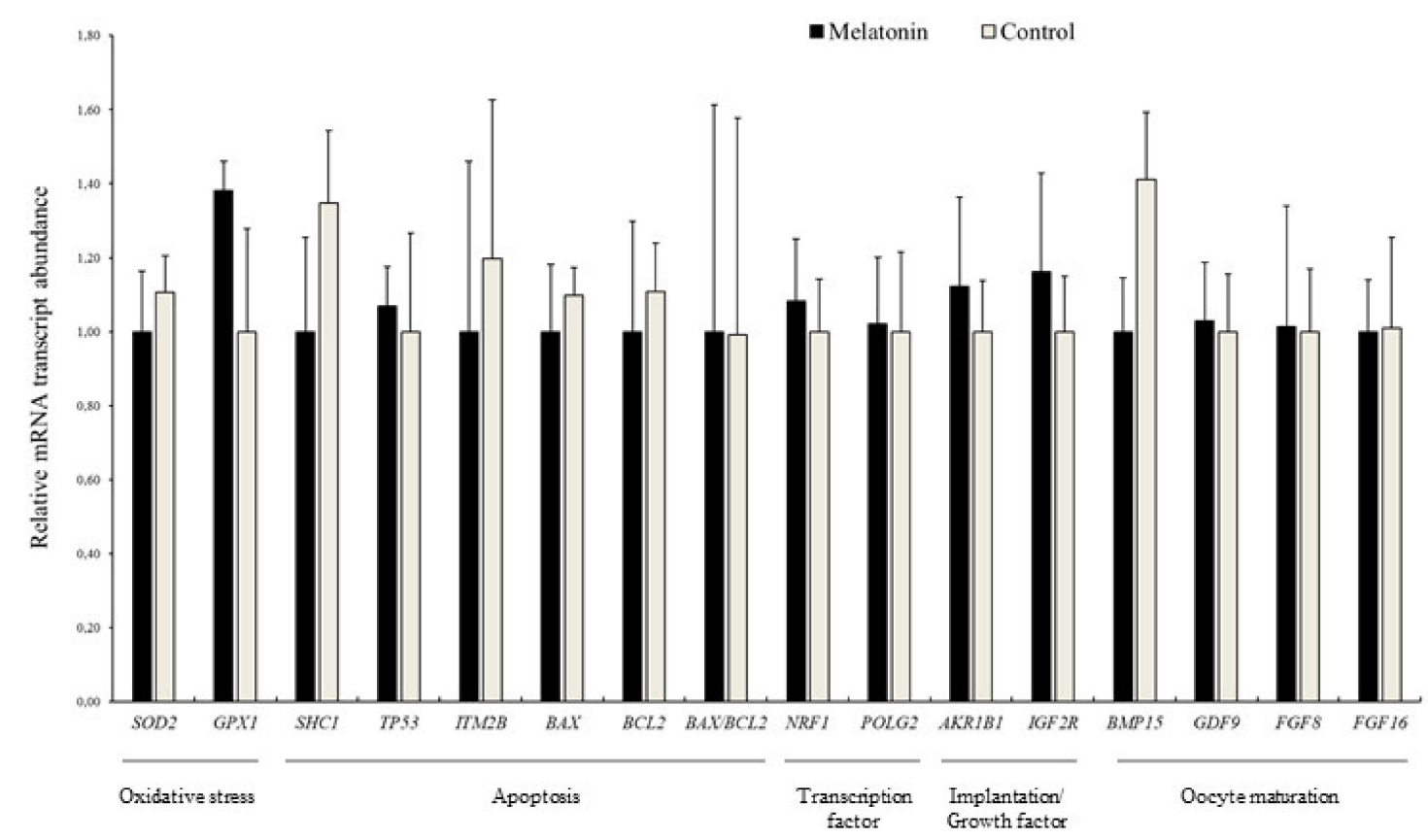

Figure 8. Relative mRNA transcript abundance in Iberian red deer oocytes collected from ovary stored with (Melatonin) and without melatonin (Control); Results are expressed as mean \pm SEM.

\subsection{Effects of Melatonin on the Meiotic Competence and Embryo Production}

The in vitro meiotic progression on sheep oocytes retrieved from ovaries stored with melatonin and saline solution is summarized in Table S1. The percentage of oocytes that stayed at the GV stage, resumed meiosis (GVBD/MI stage), and reached the MII stage were similar among experimental groups $(p>0.05)$.

The proportion of Iberian red deer oocytes that progressed to the first cleavage stage after in vitro fertilization and the percentage of blastocysts relative to the total number of oocytes was significantly increased $(p<0.05)$ in the Melatonin group compared to Control (Table 2$)$. In sheep, a similar tendency was observed as the percentage of blastocysts relative to the number of cleaved embryos was increased $(p<0.05)$ following melatonin supplementation to the transport medium (Table S2). Moreover, the total cell number in sheep blastocysts was significantly greater $(p<0.05)$ in Melatonin compared with Control sheep blastocysts (108.47 \pm 16.83 and $70.84 \pm 18.22$, respectively). 
Table 2. Effect of melatonin supplementation during ovary transport on rates of cleavage and blastocyst development in Iberian red deer.

\begin{tabular}{ccccc}
\hline \multirow{2}{*}{ Treatment } & \multirow{n}{*}{} & \multirow{2}{*}{ Cleaved Embryo at $\mathbf{4 8}$ hpi (\%) } & \multicolumn{2}{c}{ Expanded Blastocyst (\%) } \\
\cline { 3 - 5 } & & & Total & Cleaved \\
\hline Melatonin & 157 & $40.08 \pm 2.51^{\mathrm{a}}$ & $14.06 \pm 2.42^{\mathrm{a}}$ & $35.62 \pm 9.58$ \\
Control & 212 & $31.85 \pm 2.45^{\mathrm{b}}$ & $6.63 \pm 2.36^{\mathrm{b}}$ & $26.17 \pm 9.33$ \\
\hline
\end{tabular}

Data expressed as mean \pm SEM; Results represent five replicates; ${ }^{a, b}$ Different letters indicate differences $(p \leq 0.05)$ among treatments.

\subsection{Effects of Melatonin on the Relative Abundance of mRNA Transcripts in Blastocysts}

The analyses of two genes involved in ROS detoxification (SOD2 and GPX1), five related to apoptosis (SHC1, TP53, ITM2B, BAX, and BCL2), two related to mitochondrial function (NRF1 and POLG2), two related to maternal recognition of pregnancy, metabolism, and imprinting (AKR1B1 and IGF2R), one related to GAP junctions (GJA1), and a reference gene (H2AFZ) were performed in blastocysts derived from both experimental treatments. In Iberian red deer, the relative abundance of SHC1, TP53, BCL2, and AKR1B1 was less in the Melatonin group compared to Control group $(p<0.05$; Figure 9). Additionally, mRNA transcript levels in sheep blastocysts showed a lower abundance of ITM2B and $B A X / B C L 2$ ratio, and a greater abundance of $B C L 2, N R F 1$, and GJA1 in embryos from the Melatonin group $(p<0.05$; Figure S2).

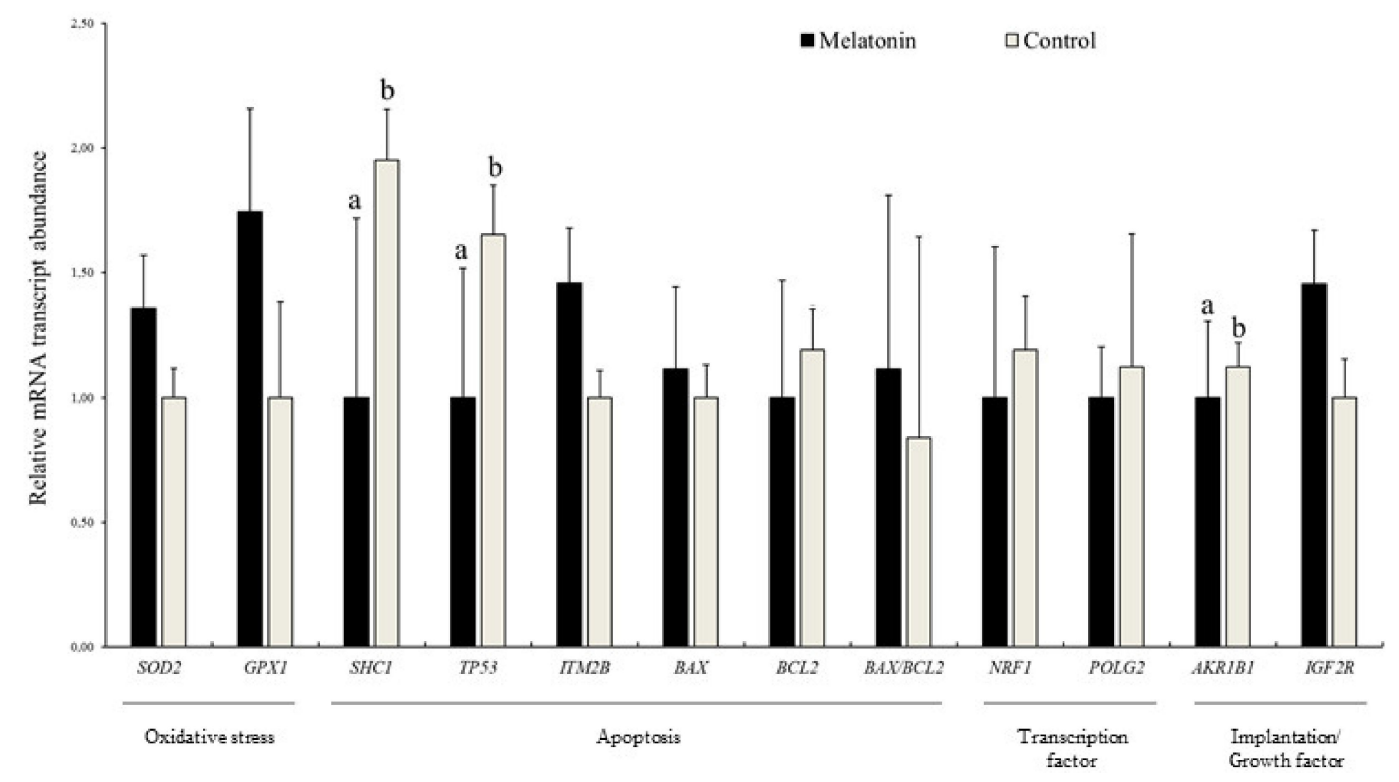

Figure 9. Relative mRNA transcript abundance in Iberia red deer blastocysts produced in vitro from ovary stored with (Melatonin) and without melatonin (Control); Results are expressed as mean \pm SEM; a,b Different letters indicate differences $(p \leq 0.05)$ among treatments.

\section{Discussion}

In vitro-produced Iberian red deer embryos are usually derived from oocytes collected from ovaries obtained at abattoirs or places located far from specialized laboratories. Thus, it usually is a long time between ovary collection and processing in the laboratory. This time interval is a determinant of the quality of oocytes in terms of nuclear maturation and developmental competence after IVM and IVF [10]. During ovary transport to the laboratory, certain factors such as medium composition, storage time, and temperature are crucial to preserve oocyte quality and ensure the success of reproduction technologies such as IVP [35]. Consequently, the present work was conducted to improve the Iberian red deer IVP protocol and its efficiency by modifying the ovary transportation 
solution with the supplementation of the antioxidant melatonin. To our knowledge, this research is the first to examine the effect of melatonin during ovary preservation on embryo production after IVP, as well as different parameters related to oxidative stress and apoptosis as indicators of the quality of matured oocytes, including the relative mRNA abundance of developmentally important genes in oocytes and blastocysts. When necessary, sheep was used as a research model given the difficulties of working with wild species such as Iberian red deer, since a considerable number of oocytes was required.

After death, the occlusion of blood flow reduces the supply of oxygen and energy to the ovaries and places them under ischemic conditions, resulting in a switch from aerobic to anaerobic cell metabolism [10]. This may induce the accumulation of ROS in the environment surrounding the oocytes and a decrease in their oxidative activity during transportation [41]. In order to complete in vitro development, follicle-enclosed oocytes must remain metabolically active while being transported from the abattoir to the laboratory [41]. Moreover, the female reproductive tissues exhibit higher metabolic rates than other adult organs in mammals [16]. Therefore, it is likely that a rapid increase in ROS production may occur not long after ischemia starts in the ovary. To suppress the detrimental effects of oxygen free radicals in the oocyte, melatonin has been previously used during IVM in several mammalian species [21,22,26,27], however, studies regarding its effect on the preservation of ovaries during shipment are lacking. Despite that, Goodarzi et al. [30] reported a positive effect of melatonin used as a supplement in the preservation solution in sheep. In the present study, greater melatonin concentrations were found in follicular fluid aspirated from sheep ovaries in the Melatonin group compared to the Control group. This finding may be explained by the fact that melatonin is an antioxidant with lipophilic and hydrophilic properties, which allows for a rapid diffusion through cell membranes $[42,43]$. Besides its physiological role in steroidogenic mechanisms in the follicular fluid, melatonin acts effectively as a free radical scavenger [44], preventing oxidative stress-mediated deterioration of oocyte quality and attenuating the defects of postovulatory aging oocytes [45,46]. Therefore, we hypothesized that the addition of this antioxidant to the transport medium may also have beneficial effects by moderating oocyte oxidative stress during long-term ovary preservation. In fact, our results revealed that the content of GSH of in vitro matured sheep oocytes transported in melatonin was greater than that of the Control oocytes.

Among the main nonenzymatic antioxidants that protect oocytes and embryos against oxidative damage, GSH plays a key role as it appears to reflect the degree of cytoplasmic maturity and quality of oocytes at the end of IVM [34]. Moreover, the addition of melatonin to the IVM medium has been shown to increase the oocyte GSH levels in cattle and pig [47,48], and ultimately promote fertilization and late embryonic development in vitro [49]. However, the pathway through which oocyte intracellular GSH protects from the damage inflicted by long-term ovary preservation remains unknown. Interestingly, our results showed that the supplementation of melatonin resulted in greater rates of embryonic development, indicating that its antioxidant potentiality during ovary storage was sustained throughout embryo cleavage until blastocyst formation. Notably, since the preimplantation embryo does not have the capacity for de novo synthesis of GSH until the blastocyst stage [49-52], during the early stages of cleavage to morula in vivo, the embryo is protected by the presence of GSH in the maternal reproductive tract [53]. For that reason, early embryos developing in vitro are more sensitive to GSH-depleting agents, even at low levels [52]. Considering this, it can be assumed that the addition of melatonin to the ovary preservation solution may have provided oocytes with large stores of GSH that subsequently stimulated embryo development in vitro.

In this research, the quality of resulting blastocysts in terms of total cell number per blastocyst in sheep was improved by the addition of melatonin to the ovary storage medium. Cell number is a crucial indicator of the development potential of an embryo, as it is directly related to cell cycle progression [54]. The greater numbers of blastomeric cells obtained in Melatonin compared to Control groups may be correlated with the increase in GSH levels observed in matured oocytes, since a positive relationship between oocyte intracytoplasmic GSH content and blastocyst cell number has 
been previously demonstrated by the addition of several thiol compounds to the IVM medium in goat [55]. Furthermore, our results are also in accordance with the investigation by Goodarzi et al. [30] in which increased blastocyst cell numbers in sheep were observed after melatonin supplementation to the ovary storage medium.

In addition, the use of melatonin in the current study also showed a positive effect on red deer blastocyst quality as presented by the lower abundances of mRNA transcripts for genes involved in oxidative stress and apoptosis. Even though the effect of culture media composition on apoptosis and oxidative stress has been extensively studied in mammalian preimplantation embryos [56,57], information regarding the impact of ovary storage medium on embryo quality is very limited. Notably, SHC adaptor protein (SHC1) is linked to increased intracellular ROS generation, cytochrome c release and apoptosis induction, leading to permanent embryo arrest [58-60]. Moreover, inhibition of SHC1 in knockout mice generates a higher ratio of reduced to oxidized glutathione (GSH/GSSG) in embryonic fibroblasts [61]. The encoded protein of the TP53 gene is a key transcription factor in cell cycle regulation and apoptosis [62]. Oxidative stress activates a TP53-transcriptional response, which promotes cell cycle arrest, ROS generation, and apoptosis [63]. Remarkably, the addition of melatonin has been shown to significantly decrease TP53 transcription levels, promoting subsequent in vitro development by accelerating the G1/S phase transition via the TP53/TP21 pathway [63]. Aldo-keto reductase family 1 , member $\mathrm{B} 1(A K R 1 B 1)$ is related to implantation failure and/or embryo resorption via PGF2 $\alpha$ synthesis, and it may also affect the embryo fate through its involvement in apoptotic pathways [64]. Hence, the greater relative abundance of SHC1, TP53, and AKR1B1 mRNA transcripts observed in Iberian red deer blastocysts derived from the Control group in the present study may be reflective of lesser quality embryos. Additionally, the results obtained in sheep point in the same direction since melatonin-derived blastocysts showed patterns of mRNA relative abundance associated with embryos of higher quality.

\section{Conclusions}

In conclusion, the supplementation of melatonin to the ovary storage medium had a positive effect on the developmental competence and blastocyst quality in Iberian red deer. As far as we are concerned, this is the first study to demonstrate a distinctive relationship between ovary preservation media composition and the relative mRNA abundance of several important genes in resulting blastocysts after IVP. Since successful embryo production depends on the maintenance of oocyte viability during transportation of the ovaries over long distances, the use of melatonin for IVP of wild species may successfully preserve the oocyte due to the induction of GSH synthesis. The present findings have important implications for solving the problems associated with the long transport times that usually cannot be avoided when working with wild species such as Iberian red deer. Thus, our research may serve as a basis for future studies on the use of melatonin and other antioxidants during ovary transport to promote the production of greater numbers of red deer embryos of higher quality.

Supplementary Materials: The following are available online at http://www.mdpi.com/2076-2615/10/5/763/s1. Figure S1: Relative mRNA transcript abundance in sheep oocytes collected from ovary stored with (Melatonin) and without melatonin (Control), Figure S2: Relative mRNA transcript abundance in sheep blastocysts produced in vitro from ovary stored with (Melatonin) and without melatonin (Control), Table S1: In vitro maturation of sheep oocytes retrieved from ovaries stored with and without melatonin, Table S2: Effect of melatonin supplementation during ovary transport on rates of cleavage and blastocyst development in sheep.

Author Contributions: I.S.-A. performed the experiments, conducted the laboratory procedures and the analysis of gene expression, collected the data, and wrote the manuscript. M.I.-C. participated in the design of the experiment and collected the data. P.P.-F., A.M.-M., J.A.O., M.R.F.-S., D.-A.M.-C., C.M., and V.M. conducted the laboratory procedures, J.J.G. participated in the revision of the manuscript, A.J.S. designed and directed the experiment and contributed to the preparation of the manuscript. All authors have read and agreed to the published version of the manuscript.

Funding: This research was funded by the Spanish Ministry of Economy and Competitiveness (AGL2017-89017-R) and Regional Government (SBPLY/17/180501/000500). M.I.-C. and A.M.-M. were supported by a Ministry of 
Economy and Competitiveness scholarship. P.P.-F. and D.-A.M.-C. were supported by a University of Castilla-La Mancha scholarship.

Conflicts of Interest: The authors declare no conflict of interest.

\section{References}

1. Berg, D.; Thongphakdee, A. In vitro Culture of Deer Embryos. In Comparative Embryo Culture; Springer: Berlin, Germany, 2006; pp. 191-208. ISBN 9781493995653.

2. García-Álvarez, O.; Maroto-Morales, A.; Berlinguer, F.; Fernández-Santos, M.R.; Esteso, M.C.; Mermillod, P.; Ortiz, J.A.; Ramon, M.; Pérez-Guzmán, M.D.; Garde, J.J.; et al. Effect of storage temperature during transport of ovaries on in vitro embryo production in Iberian red deer (Cervus elaphus hispanicus). Theriogenology 2011, $75,65-72$.

3. Martinez, J.G.; Carranza, J.; Fernandez-Garcia, J.L.; Sanchez-Prieto, C.B. Genetic Variation of Red Deer Populations under Hunting Exploitation in Southwestern Spain. J. Wildl. Manage. 2002, 66, 1273.

4. Garde, J.J.; Martínez-Pastor, F.; Gomendio, M.; Malo, A.F.; Soler, A.J.; Fernández-Santos, M.R.; Esteso, M.C.; García, A.J.; Anel, L.; Roldán, E.R.S. The application of reproductive technologies to natural populations of red deer. Reprod. Domest. Anim. 2006, 41, 93-102. [PubMed]

5. Herrick, J. Assisted reproductive technologies for endangered species conservation: developing sophisticated protocols with limited access to animals with unique reproductive mechanisms. Biol. Reprod. 2019, 100, 1158-1170. [PubMed]

6. Paramio, M.T.; Izquierdo, D. Current status of in vitro embryo production in sheep and goats. Reprod. Domest. Anim. 2014, 49, 37-48.

7. Wani, N.A.; Wani, G.M.; Khan, M.Z.; Salahudin, S. Effect of oocyte harvesting techniques on in vitro maturation and in vitro fertilization in sheep. Small Rumin. Res. 2000, 36, 63-67.

8. Sirard, M.A.; Desrosier, S.; Assidi, M. In vivo and in vitro effects of FSH on oocyte maturation and developmental competence. Theriogenology 2007, 68.

9. Sánchez-Ajofrín, I.; Iniesta-Cuerda, M.; Sánchez-Calabuig, M.J.; Peris-Frau, P.; Martín-Maestro, A.; Ortiz, J.A.; del Rocío Fernández-Santos, M.; Garde, J.J.; Gutiérrez-Adán, A.; Soler, A.J. Oxygen tension during in vitro oocyte maturation and fertilization affects embryo quality in sheep and deer. Anim. Reprod. Sci. 2020, 213,106279 .

10. Wongsrikeao, P.; Otoi, T.; Karja, N.W.K.; Agung, B.; Nii, M.; Nagai, T. Effects of ovary storage time and temperature on DNA fragmentation and development of porcine oocytes. J. Reprod. Dev. 2005, 51, 87-97.

11. Guibert, E.E.; Petrenko, A.Y.; Balaban, C.L.; Somov, A.Y.; Rodriguez, J.V.; Fuller, B.J. Organ preservation: Current concepts and new strategies for the next decade. Transfus. Med. Hemotherapy 2011, 38, 125-142.

12. Combelles, C.M.H.; Gupta, S.; Agarwal, A. Could oxidative stress influence the in-vitro maturation of oocytes? Reprod. Biomed. Online 2009, 18, 864-880. [PubMed]

13. Liang, L.F.; Qi, S.T.; Xian, Y.X.; Huang, L.; Sun, X.F.; Wang, W.H. Protective effect of antioxidants on the pre-maturation aging of mouse oocytes. Sci. Rep. 2017, 7, 1-10.

14. Torres-Osorio, V.; Urrego, R.; Echeverri-Zuluaga, J.J.; López-Herrera, A. Oxidative stress and antioxidant use during in vitro mammal embryo production: Review. Rev. Mex. Ciencias Pecu. 2019, 10, 433-459.

15. Zhau, X.; Zuo, L. Characterization of oxygen radical formation mechanism at early cardiac ischemia. Cell Death Dis. 2013, 4, e787-7.

16. Reynolds, L.P.; Grazul-Bilska, A.T.; Redmer, D.A. Angiogenesis in the female reproductive organs: Pathological implications. Int. J. Exp. Pathol. 2002, 83, 151-164.

17. Shirley, M.K.; Arthurs, O.J.; Seunarine, K.K.; Cole, T.J.; Eaton, S.; Williams, J.E.; Clark, C.A.; Wells, J.C.K. Metabolic rate of major organs and tissues in young adult South Asian women. Eur. J. Clin. Nutr. 2019, 73, 1164-1171.

18. Wang, S.; He, G.; Chen, M.; Zuo, T.; Xu, W.; Liu, X. The Role of Antioxidant Enzymes in the Ovaries. Oxid. Med. Cell. Longev. 2017. [CrossRef]

19. Tamura, H.; Nakamura, Y.; Korkmaz, A.; Manchester, L.C.; Tan, D.X.; Sugino, N.; Reiter, R.J. Melatonin and the ovary: physiological and pathophysiological implications. Fertil. Steril. 2009, 92, 328-343. 
20. Wang, F.; Tian, X.Z.; Zhou, Y.H.; Tan, D.X.; Zhu, S.E.; Dai, Y.P.; Liu, G.S. Melatonin improves the quality of in vitro produced (IVP) bovine embryos: Implications for blastocyst development, cryotolerance, and modifications of relevant gene. expression. PLOS ONE 2014, 9, 1-7.

21. El-Raey, M.; Geshi, M.; Somfai, T.; Kaneda, M.; Hirako, M.; Abdel-Ghaffar, A.E.; Sosa, G.A.; El-Roos, M.E.A.A.; Nagai, T. Evidence of melatonin synthesis in the cumulus oocyte complexes and its role in enhancing oocyte maturation in vitro in cattle. Mol. Reprod. Dev. 2011, 78, 250-262.

22. Tian, X.; Wang, F.; Zhang, L.; He, C.; Ji, P.; Wang, J.; Zhang, Z.; Lv, D.; Abulizi, W.; Wang, X.; et al. Beneficial effects of melatonin on the in vitro maturation of sheep oocytes and its relation to melatonin receptors. Int. J. Mol. Sci. 2017, 18, 834 .

23. Ishizuka, B.; Kuribayashi, Y.; Murai, K.; Amemiya, A.; Itoh, M.T. The effect of melatonin on in vitro fertilization and embryo development in mice. J. Pineal Res. 2000, 28, 48-51. [PubMed]

24. Rodriguez-Osorio, N.; Kim, I.J.; Wang, H.; Kaya, A.; Memili, E. Melatonin increases cleavage rate of porcine preimplantation embryos in vitro. J. Pineal Res. 2007, 43, 283-288. [PubMed]

25. Choi, J.; Park, S.M.; Lee, E.; Kim, J.H.; Jeong, Y.I.; Lee, J.Y.; Park, S.W.; Kim, H.S.; Hossein, M.S.; Jeong, Y.W.; et al. Anti-apoptotic effect of melatonin on preimplantation development of porcine parthenogenetic embryos. Mol. Reprod. Dev. 2008, 75, 1127-1135. [PubMed]

26. Kang, J.T.; Koo, O.J.; Kwon, D.K.; Park, H.J.; Jang, G.; Kang, S.K.; Lee, B.C. Effects of melatonin on in vitro maturation of porcine oocyte and expression of melatonin receptor RNA in cumulus and granulosa cells. J. Pineal Res. 2009, 46, 22-28. [PubMed]

27. Shi, J.M.; Tian, X.Z.; Zhou, G.; Bin Wang, L.; Gao, C.; Zhu, S.E.; Zeng, S.M.; Tian, J.H.; Liu, G.S. Melatonin exists in porcine follicular fluid and improves in vitro maturation and parthenogenetic development of porcine oocytes. J. Pineal Res. 2009, 47, 318-323.

28. Mehaisen, G.M.K.; Saeed, A.M.; Gad, A.; Abass, A.O.; Arafa, M.; El-Sayed, A.; Fraidenraich, D. Antioxidant capacity of melatonin on preimplantation development of fresh and vitrified rabbit embryos: Morphological and molecular aspects. PLoS ONE 2015, 10,1-16.

29. Mohseni, M.; Mihandoost, E.; Shirazi, A.; Sepehrizadeh, Z.; Bazzaz, J.T.; Ghazi-Khansari, M. Melatonin may play a role in modulation of bax and bcl-2 expression levels to protect rat peripheral blood lymphocytes from gamma irradiation-induced apoptosis. Mutat Res. 2012, 738-739, 19-27.

30. Goodarzi, A.; Zare Shahneh, A.; Kohram, H.; Sadeghi, M.; Moazenizadeh, M.H.; Fouladi-Nashta, A.; Dadashpour Davachi, N. Effect of melatonin supplementation in the long-term preservation of the sheep ovaries at different temperatures and subsequent in vitro embryo production. Theriogenology 2018, 106, 265-270.

31. Levraut, J.; Iwase, H.; Shao, Z.H.; Vanden Hoek, T.L.; Schumacker, P.T. Cell death during ischemia: Relationship to mitochondrial depolarization and ROS generation. Am. J. Physiol. Hear. Circ. Physiol. 2003, 284, 549-558.

32. Matsukawa,K.; Akagi, S.; Adachi, N.; Kubo, M.; Hirako, M.; Watanabe, S.; Takahashi, S. Effect of Ovary Storage on Development of Bovine Oocytes after Intracytoplasmic Sperm Injection, Parthenogenetic Activation, or Somatic Cell Nuclear Transfer. J. Mamm. Ova Res. 2007, 24, 114-119.

33. Ribeiro, B.I.; Love, L.B.; Choi, Y.H.; Hinrichs, K. Transport of equine ovaries for assisted reproduction. Anim. Reprod. Sci. 2008, 108, 171-179. [PubMed]

34. Piras, A.R.; Burrai, G.P.; Ariu, F.; Falchi, L.; Zedda, M.T.; Pau, S.; Gadau, S.D.; Antuofermo, E.; Bebbere, D.; Ledda, S.; et al. Structure of preantral follicles, oxidative status and developmental competence of in vitro matured oocytes after ovary storage at $4{ }^{\circ} \mathrm{C}$ in the domestic cat model. Reprod. Biol. Endocrinol. 2018, 16, $1-14$.

35. Barberino, R.S.; Silva, J.R.V.; Figueiredo, J.R.; Matos, M.H.T. Transport of Domestic and Wild Animal Ovaries: A Review of the Effects of Medium, Temperature, and Periods of Storage on Follicular Viability. Biopreserv. Biobank. 2019, 17, 84-90.

36. Takahashi, Y.; First, N.L. In vitro development of bovine ane-cell embryos: Influence of glucose, lactate, pyruvate, amino acids and vitamins. Theriogelology 1992, 37, 963-978.

37. Bermejo-Álvarez, P.; Rizos, D.; Rath, D.; Lonergan, P.; Gutiérrez-Adán, A. Can Bovine In Vitro-Matured Oocytes Selectively Process X- or Y-Sorted Sperm Differentially?1. Biol. Reprod. 2008, 79, 594-597.

38. Schmittgen, T.D.; Livak, K.J. Analyzing real-time PCR data by the comparative CT method. Nat. Protoc. 2008, 3, 1101-1108. 
39. Livak, K.J.; Schmittgen, T.D. Analysis of relative gene expression data using real-time quantitative PCR and the 2- $\Delta \Delta \mathrm{CT}$ method. Methods 2001, 25, 402-408.

40. Ferreira, R.M.; Chiaratti, M.R.; Macabelli, C.H.; Rodrigues, C.A.; Ferraz, M.L.; Watanabe, Y.F.; Smith, L.C.; Meirelles, F.V.; Baruselli, P.S. The Infertility of Repeat-Breeder Cows During Summer Is Associated with Decreased Mitochondrial DNA and Increased Expression of Mitochondrial and Apoptotic Genes in Oocytes1. Biol. Reprod. 2016, 94, 1-10.

41. Tellado, M.N.; Alvarez, G.M.; Dalvit, G.C.; Cetica, P.D. The Conditions of Ovary Storage Affect the Quality of Porcine Oocytes. Adv. Reprod. Sci. 2014, 02, 56-67.

42. Costa, E.J.X.; Lopes, R.H.; Lamy-Freund, M.T. Permeability of pure lipid bilayers to melatonin. J. Pineal Res. 1995, 19, 123-126. [PubMed]

43. Tamura, H.; Takasaki, A.; Taketani, T.; Tanabe, M.; Kizuka, F.; Lee, L.; Tamura, I.; Maekawa, R.; Aasada, H.; Yamagata, Y.; et al. The role of melatonin as an antioxidant in the follicle. J. Ovarian Res. 2012, 26, 5.

44. Adriaens, I.; Jacquet, P.; Cortvrindt, R.; Janssen, K.; Smitz, J. Melatonin has dose-dependent effects on folliculogenesis, oocyte maturation capacity and steroidogenesis. Toxicology 2006, 228, 333-343. [PubMed]

45. Nie, J.; Xiao, P.; Wang, X.; Yang, X.; Xu, H.; Lu, K.; Lu, S.; Liang, X. Melatonin prevents deterioration in quality by preserving epigenetic modifications of porcine oocytes after prolonged culture. Aging (Albany. NY). 2018, 10, 3897-3909. [PubMed]

46. Ramis, M.; Esteban, S.; Miralles, A.; Tan, D.; Reiter, R. Protective Effects of Melatonin and Mitochondria-targeted Antioxidants Against Oxidative Stress: A Review. Curr. Med. Chem. 2015, 22, 2690-2711. [PubMed]

47. Yang, M.; Tao, J.; Chai, M.; Wu, H.; Wang, J.; Li, G.; He, C.; Xie, L.; Ji, P.; Dai, Y.; et al. Melatonin improves the quality of inferior bovine oocytes and promoted their subsequent IVF embryo development: Mechanisms and results. Molecules 2017, 22, 12.

48. Yang, L.; Wang, Q.; Cui, M.; Li, Q.; Mu, S.; Zhao, Z. Effect of Melatonin on the In Vitro Maturation of Porcine Oocytes, Development of Parthenogenetically Activated Embryos, and Expression of Genes Related to the Oocyte Developmental Capability. Animals 2020, 10, 209.

49. De Matos, D.G.; Furnus, C.C.; Moses, D.F.; Baldassarre, H. Effect of cysteamine on glutathione level and developmental capacity of bovine oocyte matured in vitro. Mol. Reprod. Dev. 1995, 42, 432-436.

50. Gardiner, C.S.; Reed, D.J. Synthesis of glutathione in the preimplantation mouse embryo. Arch. Biochem. Biophys. 1995, 318, 30-36.

51. Guérin, P.; El Mouatassim, S.; Ménézo, Y. Oxidative stress and protection against reactive oxygen species in the pre-implantation embryo and its surroundings. Hum. Reprod. Update 2001, 7, 175-189.

52. Lee, C.S.; Koo, D.B.; Fang, N.; Lee, Y.; Shin, S.T.; Park, C.S.; Lee, K.K. Potent and stage-specific action of glutathione on the development of goat early embryos in vitro. Mol. Reprod. Dev. 2000, 57, 48-54. [PubMed]

53. Gardiner, C.S.; Salmen, J.J.; Brandt, C.J.; Stover, S.K. Glutathione is present in reproductive tract secretions and improves development of mouse embryos after chemically induced glutathione depletion. Biol. Reprod. 1998, 59, 431-436. [PubMed]

54. Kong, X.; Yang, S.; Gong, F.; Lu, C.; Zhang, S.; Lu, G.; Lin, G. The relationship between cell number, division behavior and developmental potential of cleavage stage human embryos: A time-lapse study. PLoS ONE 2016, 11, 1-11.

55. Rodríguez-González, E.; López-Bejar, M.; Mertens, M.J.; Paramio, M.T. Effects on in vitro embryo development and intracellular glutathione content of the presence of thiol compounds during maturation of prepubertal goat oocytes. Mol. Reprod. Dev. 2003, 65, 446-453.

56. Esfandiari, N.; Falcone, T.; Agarwal, A.; Attaran, M.; Nelson, D.R.; Sharma, R.K. Protein supplementation and the incidence of apoptosis and oxidative stress in mouse embryos. Obstet. Gynecol. 2005, 105, 653-660.

57. Takahashi, M. Oxidative stress and redox regulation on in vitro development of mammalian embryos. J. Reprod. Dev. 2012, 58, 1-9.

58. Giorgio, M.; Migliaccio, E.; Orsini, F.; Paolucci, D.; Moroni, M.; Contursi, C.; Pelliccia, G.; Luzi, L.; Minucci, S.; Marcaccio, M.; et al. Electron transfer between cytochrome $\mathrm{c}$ and p66Shcgenerates reactive oxygen species that trigger mitochondrial apoptosis. Cell 2005, 122, 221-233.

59. Favetta, L.A.; St. John, E.J.; King, W.A.; Betts, D.H. High levels of p66shcand intracellular ROS in permanently arrested early embryos. Free Radic. Biol. Med. 2007, 42, 1201-1210. 
60. Betts, D.H.; Bain, N.T.; Madan, P. The p66Shc adaptor protein controls oxidative stress response in early bovine embryos. PLOS ONE 2014, 9, 1.

61. Soliman, M.A.; Abdel Rahman, A.M.; Lamming, D.A.; Birsoy, K.; Pawling, J.; Frigolet, M.E.; Lu, H.; Fantus, I.G.; Pasculescu, A.; Zheng, Y.; et al. The adaptor protein p66Shc inhibits mTOR-dependent anabolic metabolism. Sci. Signal. 2014, 7, 1-11.

62. Vousden, K.H.; Prives, C. Blinded by the Light: The Growing Complexity of p53. Cell 2009, 137, $413-431$. [PubMed]

63. Pan, B.; Yang, H.; Wu, Z.; Qazi, I.H.; Liu, G.; Han, H.; Meng, Q.; Zhou, G. Melatonin improves parthenogenetic development of vitrified-warmed mouse oocytes potentially by promoting G1/S cell cycle progression. Int. J. Mol. Sci. 2018, 19, 1-16.

64. El-Sayed, A.; Hoelker, M.; Rings, F.; Salilew, D.; Jennen, D.; Tholen, E.; Sirard, M.-A.; Schellander, K.; Tesfaye, D. Large-scale transcriptional analysis of bovine embryo biopsies in relation to pregnancy success after transfer to recipients. Physiol. Genomics 2006, 28, 84-96. [PubMed]

(C) 2020 by the authors. Licensee MDPI, Basel, Switzerland. This article is an open access article distributed under the terms and conditions of the Creative Commons Attribution (CC BY) license (http://creativecommons.org/licenses/by/4.0/). 